
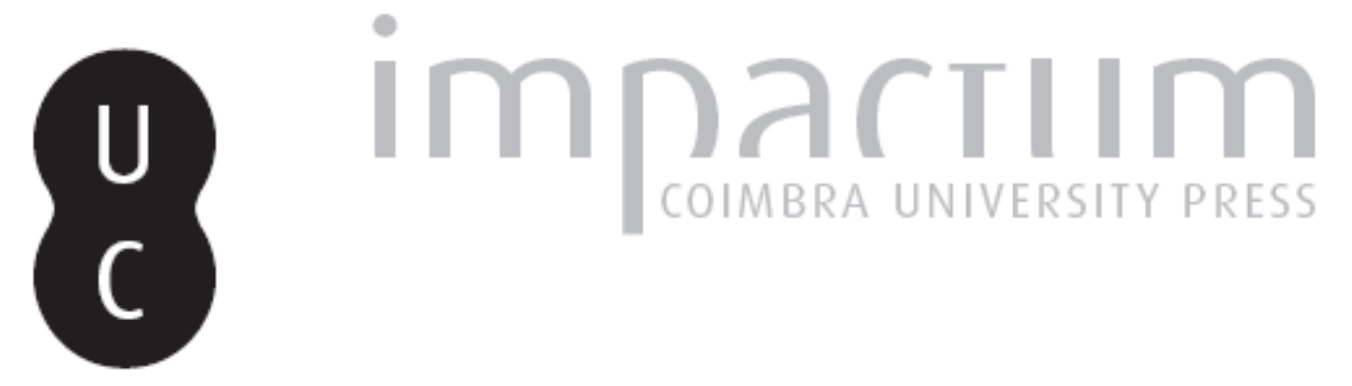

\title{
Ideologia e indústria: a exposição distrital de Coimbra em 1884
}

Autor(es): Homem, Amadeu José de Carvalho

Publicado por: Imprensa da Universidade de Coimbra

URL persistente:

URI:http://hdl.handle.net/10316.2/43840

DOI:

DOI:https://doi.org/10.14195/2183-8925_6_12

Accessed : $\quad$ 26-Apr-2023 11:11:12

A navegação consulta e descarregamento dos títulos inseridos nas Bibliotecas Digitais UC Digitalis, UC Pombalina e UC Impactum, pressupõem a aceitação plena e sem reservas dos Termos e Condições de Uso destas Bibliotecas Digitais, disponíveis em https://digitalis.uc.pt/pt-pt/termos.

Conforme exposto nos referidos Termos e Condições de Uso, o descarregamento de títulos de acesso restrito requer uma licença válida de autorização devendo o utilizador aceder ao(s) documento(s) a partir de um endereço de IP da instituição detentora da supramencionada licença.

Ao utilizador é apenas permitido o descarregamento para uso pessoal, pelo que o emprego do(s) título(s) descarregado(s) para outro fim, designadamente comercial, carece de autorização do respetivo autor ou editor da obra.

Na medida em que todas as obras da UC Digitalis se encontram protegidas pelo Código do Direito de Autor e Direitos Conexos e demais legislação aplicável, toda a cópia, parcial ou total, deste documento, nos casos em que é legalmente admitida, deverá conter ou fazer-se acompanhar por este aviso.

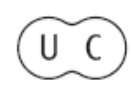




\section{REVISTA DE HISTORIA DAS IDEIAS 6}

\section{. \\ REVOLTAS E REVOLUCOEES}

*

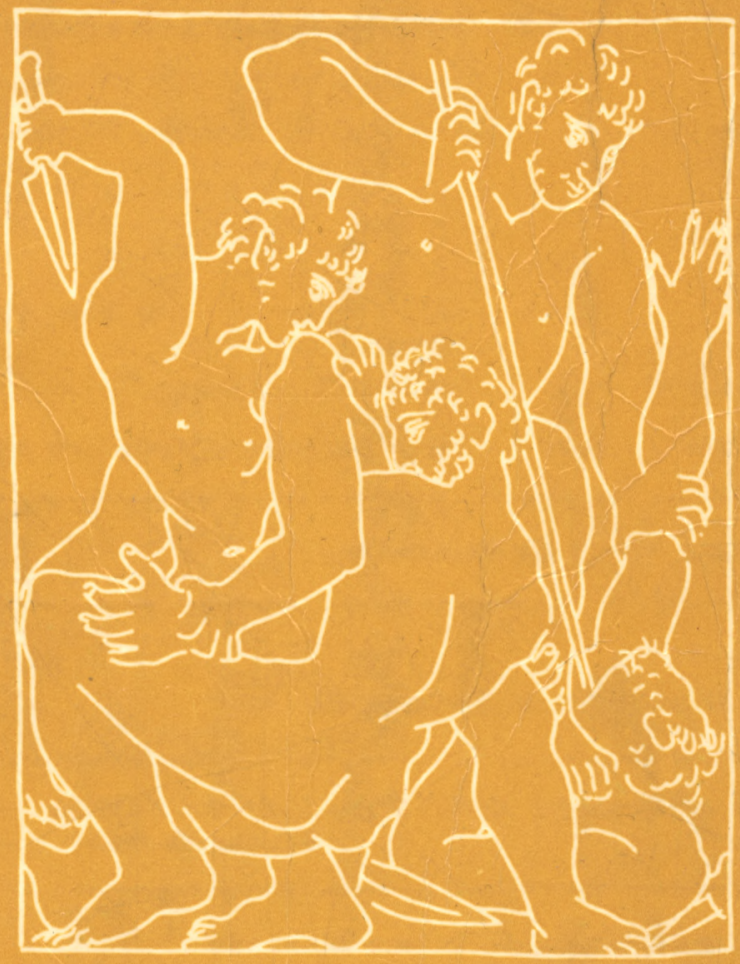

INSTITUTO DE HISTORIA E TEORIA DAS IDEIAS FACULDADE DE LETRAS 


\title{
IDEOLOGIA E INDÚSTRIA
}

\section{A EXPOSIÇÃO DISTRITAL DE COIMBRA EM $1884^{* *}$}

\begin{abstract}
O advento da grande indústria contemporânea, possibilitado pelo conjunto das inovações tecnológicas introduzidas nos processos de fabricação nos fins do século XVIII e no decurso da primeira metade do século XIX, converteu a Europa num verdadeiro laboratório de análise social. $\mathbf{A}$ indústria, com o conjunto das suas novas características de concentração financeira e de produção em grande escala, foi questionada e diversamente interpretada pelos mais conspícuos representantes de correntes de opinião em conflito. Por um lado, os tradicionalistas, saudosos da estratificação social anterior, encaravam este desenvolvimento industrial com o maior dos cepticismos, acusando-o de contribuir para a dissolução dos laços patriarcais de solidariedade que se tinham constituído em torno da grande propriedade fundiária; e, vendo estabelecer-se lentamente um vínculo de ligação entre as unidades produtivas e as grandes cidades, apresentavam a desertificação dos campos e o abandono da agricultura como a pior das desgraças, senão mesmo como um ímpio atentado às leis do Criador. Como é de supor, estes receios não eram compartilhados pelos defensores do horizonte liberal, que, com maior ou menor cópia de argumentos, referiam as superioridades do ritmo produtivo e as possibilidades de erradicação fácil da miséria. Como herdeiros directos ou espúrios da revolução de 1789 , os defensores do industrialismo antepunham à solidariedade tradicionalista, baseada na propriedade imobíliária, 0
\end{abstract}

* Faculdade de Letras da Universidade de Coimbra.

** Conferência proferida em 1 de Julho de 1984, no ámbito do $1 .^{\circ}$ Centenário da Exposição Distrital de 1884, em Coimbra. 
princípio individualista do "laissez-faire» $e$ as virtudes da mobilidade pecuniária. Distinguia-se, finalmente, uma outra corrente de opinião, de contornos um tanto mais fluidos, formada por aqueles que não repudiavam liminarmente o novo sentido da economia, mas desejavam vê-la depurada dos seus excessos egoístas e da sua dinâmica impessoal e instrumentalizadora. Oscilava-se aqui, conforme o grau de radicalismo adoptado, entre a pregação agrário-comunista, na linha de Babeuf e de Buonarroti, e a exortação comunitária neo-jacobina, sem esquecer também o significado e o sentido da declamação místico-filantrópica.

Pretende-se com tudo isto dizer que os problemas do crescimento industrial e da nova organização do processo produtivo se encontram no cerne das preocupações da Europa oitocentista, oferecendo aos teorizadores sociais e à simples opinião pública todos os pretextos para que em seu redor se organize o debate e cresça a controvérsia.

Deixemos de parte a opção tradicionalista já que, pelo menos quanto aos exactos termos em que começou por ser formulada, foi definitivamente suplantada pelo próprio dinamismo do processo histórico. A crença optimista nas possibilidades da indústria para a melhoria das condições materiais da espécie humana, encarada como um todo e não no seu fraccionamento de classes e grupos heterogéneos, encontra-se explanada, no exemplo francês a que vamos recorrer, na obra de Saint-Simon, e sobretudo na opinião de alguns saint-simonianos, seus discípulos. No caso particular do fundador da escola, este industrialismo optimista acha-se articulado com um plano de reorganização social e científica susceptível de aniquilar os últimos vestígios da feudalidade e de transferir para as mãos de tecnocratas esclarecidos o conjunto dos poderes decisórios. A enorme relevância que Claude-Henri de Saint-Simon atribui à indústria expressa-se desde logo num conjunto de opúsculos por ele publicados entre 1816 e 1822 e cujos títulos genéricos falam por si: L'Industrie (1816-1818), L'Organisateur (1819-1820) e Du Système Industriel (1820-1822) ( ${ }^{1}$. . A tónica industrialista e liberalizante destas produções do Conde de Saint-Simon ampara-se com o recurso à autoridade dos princípios económicos definidos pelo «imortal Smith" e consolidados por Jean Baptiste Say. Em todas estas pequenas produções se detecta como inimigo principal a figu-

(') Cf. Henri Gouhier, La jeunesse d'Auguste Comte et la formation du positivisme III. Auguste Comte et Saint-Simon, Paris, Librairie Philosophique J. Vrin, 1941, pp. 31-48. 
ra do nobre, zangão ocioso criado na colmeia do Antigo Regime e no favo das rendas fundiárias percebidas sem trabalho $\left({ }^{2}\right)$. $\mathrm{O}$ que nesta altura ainda não surge, sendo necessário aguardar pelas suas últimas produções, é a suspeita de que a própria comunidade activa possa comportar contradições insanáveis, nascidas dos interesses e dos estatutos sociais contraditórios. E é assim que no tomo IV da colectânea intitulada L'Industrie o seu autor dá por demonstrados três grandes princípios:

$$
\begin{aligned}
& \text { «1. - Que la classe industrielle est la seule classe } \\
& \text { utile; } \\
& 2 .^{\circ} \text { - Que cette classe devient continuellement plus } \\
& \text { nombreuse, et que, s'accroissant toujours aux } \\
& \text { dépens des autres, elle doit finir par devenir } \\
& \text { la classe unique; } \\
& 3 .^{\circ} \text { - Que toutes les lois, ainsi que toutes les me- } \\
& \text { sures administratives pouvaient être bien ju- } \\
& \text { gées en les considérant sous cet unique rap- } \\
& \text { port: sont-elles utiles ou nuisibles à l'indus- } \\
& \text { trie? et que c'était même la seule manière de } \\
& \text { les juger sainement.» }\left({ }^{3}\right),
\end{aligned}
$$

No termo da sua carreira filosófica, e mais particularmente na elaboração do Catéchisme des Industriels e do Nouveau Christianisme, Saint-Simon parece despertar para o facto das virtualidades da indústria nem sempre funcionarem em favor da classe mais numerosa e mais pobre, ao lado da qual pretendeu finalmente colocar-se. Esta aparente discrepância permite que o conteúdo das suas propostas possa ser continuada em dois sentidos diferentes, quando não mesmo acentuadamente opostos. Um deles, fazendo tábua rasa da teofilantropia do seu remate final, converterá a indústria numa espécie de enorme cornucópia de que manarão todas as primícias de bem estar e de felicidade colectiva; o outro, mais atento à inflexão final do seu discurso, repercutirá esse fundo ético-social e abordará o gigantismo industrial com uma mais cautelosa reserva. Acreditamos que esta dupla herança ideo-

(2) Esta noção exprime-se claramente em dois opúsculos publicados por Saint-Simon em Abril de 1819, sob os títulos Le Parti National ou Industriel comparé au Parti Anti-National e Sur la querelle des abeilles et des frelons. Vide Oeuvres de Claude-Henri de Saint-Simon, t. 2. ${ }^{\circ}$, Genève, Slatkine Reprints, 1977, pp. 195-209 e 211-234.

(3) Saint-Simon, L'Industrie, in Oeuvres de Claude-Henri de Saint-Simon, t. 2. ${ }^{\circ}$ Genève, Slatkine Reprints, 1977, p. 74. 
lógica se encontra representada na filosofia social francesa, a primeira através dos que constituíram a chamada escola ou igreja saint-simoniana, com particular relevância para Prosper Enfantin e Michel Chevalier e a segunda, de recorte socializante e cooperativista, através dos nomes de Pierre Leroux, Buchez e Bazard ( $\left.{ }^{4}\right)$.

O que, seja como for, parece estar já definitivamente assente é a co-autoria de alguns herdeiros de Saint-Simon no florescimento do grande capitalismo francês. Basta recordar a responsabilidade directa, neste desenvolvimento, de alguns banqueiros saint-simonianos, como os irmãos Péreire, para já não falar no saint-simonismo de juventude de Luís Napoleão Bonaparte, sob cujo poder cesarista as forças produtivas se foram organizando monopolisticamente $\left({ }^{5}\right)$.

Também Portugal conheceu a sua versão doméstica de liberalismo industrialista, o seu pseudo-saint-simonismo. Chamou-se Regeneração ou Fontes Pereira de Melo, conforme se prefira designar o movimento histórico ou a personalidade de proa que o tentou viabilizar. $O$ ano de 1851 encerra, em França e em Portugal, o ciclo das promessas democráticas nascidas do romantismo social de 1848 . Em ambos os casos, a indústria, neutra em si mesma, enquanto puro processo técnico, se irá identificar cada vez mais com os estratos sociais das grandes burguesias, ontem amedrontradas, hoje vitoriosas e instaladas. Uma vez ultrapassados os escolhos das objecções primitivas, o século XIX irá ser, sobretudo na sua segunda metade, o século da glorificação da indústria. E ela a "razão prática" de uma espécie de neo-iluminismo proficiente e activo, escorado no culto das "capacidades" e no desvelo com que são tratadas as "virtudes» da sisudez negocial, da poupança privada e da livre concorrência. Esta mundividência, de inegável quilate burguês, alcançará entre nós uma fácil hegemonia, tanto mais que a política fontista dos «melhoramentos materiais» encontrará no rotativismo partidário o expediente legal com que satisfará o anseio dominante de viver liberalmente na aparência e plutocraticamente na essência das coisas $\left(^{8}\right)$.

(4) Cf. G.D.H. Cole, Historia del pensamiento socialista I. Los precursores (1789-1850), Buenos Aires, Fondo de Cultura Economica, 1957, pp. 58-68.

(') Cf. Charles Morazé, Les bourgeois conquérants, Paris, Librairie Armand Colin, 1957, pp. 251-264.

(') Temos bem presente que a febre financista das burguesias portuguesas no período posterior à Regeneração se traduziu invariavelmente no comodismo estéril da corretagem e dos jogos de Bolsa, com exclusão dos rasgados propósitos industrialistas que moveram os 
Em 1851, ano em que Napoleão III liquida o remanescente da herança de 1848 pelo golpe de estado de Dezembro e em que Portugal inicia o seu período de estabilização burguesa com o movimento regenerador saldanhista, realiza a Inglaterra a primeira exposição internacional da indústria. A partir daqui, inaugura-se uma longa série de empreendimentos, desta natureza, de que sobressaem, pela imponência das instalações, pelo número de expositores e pela afluência de visitantes, a Exposição Internacional de Filadélfia de 1876, as Exposições Internacionais de Paris de 1876, de 1889 e de 1900 e a Exposição Internacional de Chicago de 1893 . Na sua esmagadora maioria, estas Exposições, que se sucedem, em catadupa, até aos finais do século e que continuam a realizar-se no período seguinte, são promovidas pelos governos centrais dos diversos países. Com elas se pretende aferir periodicamente o grau de desenvolvimento produtivo, alargar mercados, cotejar processos tecnológicos, celebrar efemérides e até glorificar regimes políticos. Algumas houve que maravilharam os visitantes da época com a magnificência de obras de arte e de engenharia expressamente criadas para o efeito. Foi o caso da já referida exposição londrina de 1851, para a qual se edificou o "Crystal Palace», da exposição parisiense de 1878, para a qual se erigiu o palácio do Trocadero, e sobretudo da Exposição Internacional de 1889 , comemorativa do centenário da Revolução Francesa, que teve como grande motivo de atracção a Torre Eiffel, encarada na altura como um verdadeiro símbolo do progresso tecnológico e industrial. Esta última exposição foi acolhida com grandes reticências pelos governos monárquicos europeus, dado o significado político que não poderia deixar de se lhe atribuir. Apesar disso, atingiu um brilho excepcional, podendo mesmo dizer-se que ela constituiu um dos factos mais notáveis da história da indústria internacional oitocentista. E valerá a pena dizer que o nosso país esteve nela representado com muita evidência. Fomos a terceira deputação estrangeira mais numerosa, com 2.005 expositores, número apenas superado pelo México e pela Espanha.

saint-simonianos do segundo Império francês. Assim se compreende a asserção da Oliveira Martins, em 1881: "Uma granja e um Banco: eis o Portugal, português. Onde está a oficina?» (Oliveira Martins, Portugal Contemporâneo, t. 2. ${ }^{\circ}$, Lisboa, Guimarães Editores, 8. ${ }^{\mathrm{a}}$ ed., p. 331). Mas foi esta, apesar de tudo, a versão do capitalismo indígena... 
Embora estes certames se saldassem por uma glorificação abstracta do trabalho humano, não dando margem a que os poderes públicos contra eles manifestassem especiais prevenções, o certo é que nem sempre as coisas se passaram dentro das balizas da neutralidade ideológica. Com efeito, as exposições industriais, especialmente as de dimensão internacional, forneceram algumas vezes aos trabalhadores a favorável oportunidade de realizarem uma reflexão conjunta sobre a sua condição económica, a sua representatividade social e o grau e limites da sua intervenção política. Desta tomada de consciência puderam gerar-se, em alguns casos, propostas alternativas de organização laboral e de reformulação legislativa ou mesmo projectos concretos de criação de associações agremiando trabalhadores de diversos países. Como é sabido, foi do contacto das delegações estrangeiras com o bem organizado sindicalismo "trade-unionista» britânico que nasceu, por ocasião da Exposição Internacional de Londres de 1862, a proposta autonómica do internacionalismo operário, a breve trecho concretizada com a fundação da Associação Internacional dos Trabalhadores $\left({ }^{7}\right)$.

Pelo que concerne a Portugal, o panorama das realizações deste tipo é bastante mais pobre. A exposição manufactureira que o Marquês de Pombal organizou em Oeiras, nos anos de 1775 e 1776, passa por ser a precursora das Exposições industriais da centúria seguinte. Seja assim ou não, a verdade é que no decurso do século XIX foram poucos os empreendimentos congéneres de significativa dimensão nacional. Aponta-se como exposição de algum vulto a que se realizou em Lisboa no ano de 1840, com o patrocínio da Sociedade Promotora da Indústria Nacional. Mas foi só em 1865, ou seja, em plena maré alta da estabilização regeneradora, que Portugal promoveu a sua primeira exposição internacional, no Porto, onde, à semelhança do que ocorrera em Londres em 1851, se edificou também expressamente um «Palácio de Cristal».

Volvidos quatro anos sobre a data da realização do nosso primeiro certame internacional da indústria, a Associação dos Artistas de Coimbra, impulsionada por Olímpio Nicolau Rui Fernandes, realiza uma exposição de âmbito distrital, com assinalável sucesso. $\mathbf{O}$ exemplo, porém, não frutificou: entre 1869 e 1884 esta cidade não conheceu outra realização similar. Ela só irá surgir neste último ano, por iniciativa da Escola Livre das Artes do Desenho e com o cora-

(') Cf. Edouard Dolléans, Histoire du mouvement ouvrier 1830-1871, t. 1. ${ }^{\circ}$, Paris, Librairie Armand Colin, 7.. ${ }^{a}$ ed., pp. 265-273. 
joso empenho de uma numerosa comissão de figuras gradas desta cidade, avultando dentre elas os nomes de dois conimbricenses prestantes e exemplares: Joaquim Martins de Carvalho e António Augusto Gonçalves $\left({ }^{8}\right)$.

Tracejemos sobre eles algumas breves notas biográficas.

Joaquim Martins de Carvalho nasce em Coimbra, em 19 de Novembro de 1822. Os seus biógrafos assinalam a curiosidade de ter visto a luz do mundo na data em que se cerravam para sempre os olhos do patriarca da revolução vintista, Manuel Fernandes Tomás, cujo ideário Joaquim Martins de Carvalho recolheria com acrisolada devoção e pelo qual se bateria incansavelmente durante toda a sua vida. Desde logo condenado à mediocridade financeira pelos direitos de primogenitura de um seu irmão e, por isso, destinado pelos seus pais à carreira do sacerdócio católico, o futuro decano dos jornalistas portugueses ver-se-ia obrigado a enfrentar desde muito cedo a dureza da vida. Orfão desde a mais tenra idade e impedido, por isso, de prosseguir os seus estudos com regularidade, Joaquim Martins de Carvalho exerceria na sua juventude as modestas profissões de empregado comercial e de funileiro, antes de conquistar na carreira do jornalismo, por mérito próprio, um lugar cimeiro e relevantíssimo. Os seus futuros adversários políticos, supondo deprimi-lo ou minimizá-lo, irão lembrar-lhe a sua humildade profissional de origem, chamando-lhe o "Doutor das latas», designação que ele próprio não repele e de que sempre se vangloriará. $\mathrm{Na}$ luta contra o cabralismo, Joaquim Martins de Carvalho irá evidenciar conviç̧ões políticas da maior intransigência democrática, batendo-se na primeira linha pelas reclamações do chamado "partido patuleia». Entre Fevereiro e Junho de 1847 paga no cárcere do Limoeiro o tributo do seu indefectível amor à Liberdade, podendo imaginar-se que a prisão se prolongaria por muito mais tempo se o clausulado da Convenção do Gramido não impusesse à realeza a libertação dos presos. Joaquim Martins de Carvalho desempenhará também um papel muito activo no ano seguinte, quando em Coimbra decorrem secretamente os trabalhos de organização da Carbonária Lusitana. Dentro

( $\left.{ }^{8}\right)$ Presidida por Joaquim Martins de Carvalho e secretariada por António Augusto Gonçalves e Manuel Augusto Rodrigues da Silva, a comissão promotora da Exposição incluía ainda os seguintes nomes: António José da Costa, Arnaldo Augusto de Sousa Dória, Cassiano Augusto Martins Ribeiro, Estêvão Parada, José Lúcio Dias, Manuel José da Costa Soares e Severino Lopes Guimarães (cfr. Joaquim Martins de Carvalho, «Comissão», Conimbricense, n. ${ }^{\circ} 3755,11-8-18883$, p. 1, col. 4). 
dos círculos carbonários, o futuro redactor do Conimbricense era o Benigno Primo "Ledru Rollin» e desempenhou os cargos de 1..$^{\circ}$ secretário da Barraca Igualdade e de Orador da Choça 16 de Maio. Esta choça, cumprindo instruções da Alta Venda, ponderou, em Dezembro de 1848, sobre a melhor forma de governo para Portugal, tendo preferido, por unanimidade, a forma republicana. A Choça 16 de Maio reorganizou-se sob o nome de Choça Segredo, quando pressentiu a possibilidade do seu desmantelamento, por ter sido descoberto o lugar habitual das suas reuniões. Joaquim Martins de Carvalho foi então nomeado seu Presidente.

Historiador autodidacta, polemista corajoso e publicista de grande envergadura, Joaquim Martins de Carvalho desenvolveria nas trabalhosas lides do jornalismo os vários aspectos do seu admirável talento. Colaborou, primeiro, no Observador, jornal fundado em Coimbra, em 16 de Novembro de 1847. Depois, resolvido a furtar-se às pressões de notáveis locais a quem a sua independência incomodava, e que ameaçavam limitar-lhe a plena expressão do seu pensamento, fundou o Conimbricense. Este jornal veio substituir, sem solução de continuidade, o antigo Observador, surgindo o seu primeiro número em 24 de Janeiro de 1854. A vida de Joaquim Martins de Carvalho passará, a partir deste momento, a identificar-se inteiramente com a do seu jornal, do mesmo modo que este reflectirá com o maior rigor as aspirações, projectos e iniciativas do burgo coimbrão e da sua zona de influência. Ficaram memoráveis algumas das campanhas sustentadas pelo Conimbricense e indeléveis os efeitos por elas obtidos nas consciências mais esclarecidas. Assim, logo após o seu aparecimento, o Conimbricense, através da pena do seu proprietário e principal redactor, desfere os mais certeiros golpes contra o banditismo que infestava a região das Beiras, invectivando a impunidade criminosa dos malfeitores João Brandão e António Rodrigues, o Boa Tarde. Estes marginais gozavam da tolerância e talvez da discreta proteç̧ão de influentes políticos, que os utilizavam nos seus processos de galopinagem eleitoral. Assim, o protesto solene de Martins de Carvalho, que publicou nas colunas do seu jornal a lista completa das deploráveis façanhas de João Brandão, reforçou a sua impopularidade política junto dos círculos mais afectados e fomentou contra si a animosidade desses criminosos, que chegaram mesmo a projectar a sua eliminação física. Mas não foi apenas neste momento que o notável jornalista deu provas da sua alta consciência cívica e da sua indómita coragem. Uma e outra estiveram presentes nas numerosas controvérsias travadas contra o legitimismo miguelista e contra o clericalismo ultra- 
montano. Como historiador do liberalismo, Joaquim Martins de Carvalho estampou no Conimbricense, sob a forma de artir gos de fundo e de notas soltas, os volumosos resultados das suas pacientes investigações, comprovando uma competência científica que nada ficava a dever ao mais escrupuloso especialista universitário. Quando a morte o ceifou, em 18 de Outubro de 1898, não era apenas Coimbra que pranteava um dos seus mais dedicados filhos, mas também a opinião genuinamente liberal que via sumir-se uma das suas mais sonoras e cristalinas vozes $\left({ }^{9}\right)$.

Quanto a António Augusto Gonçalves, mais novo do que Joaquim Martins de Carvalho, nasceu em Coimbra, a 19 de Dezembro de 1848. Herdou de seu pai, pintor de arte e decorador com alguns merecimentos, uma fina sensibilidade estética e um critério de apreciação que irá aplicar na pedagogia e na vulgarização artísticas. Concluidos os seus estudos secundários, frequentou na Universidade de Coimbra o curso de Farmácia, que logo abandonou. A partir de então passa a dedicar-se ao ensino livre do Desenho e da Matemática, ao mesmo tempo que irá alargando o campo dos seus conhecimentos artísticos. Belisário Pimenta, que com ele de perto privou, traça-nos em breves mas esclarecedoras linhas o perfil da sua mentalidade: "tinha contra si a mácula das suas ideias ao tempo muito avançadas em política e a outra mácula não menor da falta de crenças religiosas; de modo que o seu atrevimento em não seguir os cânones pedagógicos oficiais em Arte, o seu tolerante republicanismo apenas de princípios embora firmes e o não menos tolerante livre-pensamento, teriam, na época, ressonância verdadeiramente revolucionária» $\left({ }^{10}\right)$. Neste testemunho falta apenas a alusão ao enternecimento que lhe mereciam as camadas populares mais humildes e o operariado carecido de instrução.

0 temperamento fundamentalmente artístico de António Augusto Gonçalves não o converte num contemplativo bisonho

( ${ }^{\circ}$ Cf. Alberto Martins de Carvalho, Joaquim Martins de Carvalho (Apontamentos biográficos), Coimbra, Tipografia Popular, 1916; Alberto Martins de Carvalho, Joaquim Martins de Carvalho - Apontamentos biográficos, Coimbra, Imprensa Académica, 1924, $4 .^{\mathrm{a}} \mathrm{ed}$. aumentada; Francisco Augusto Martins de Carvalho, Algumas horas na minha livraria, Coimbra, Imprensa Académica, 1910, pp. 99-106; Martins de Carvalho, in «Portugal - Diccionario historico, chorographico, biographico, heraldico, numismatico e artistico», t. $4 .^{\circ}$, Lisboa, João Romano Torres e C.a Editores, 1909, pp. 884-86.

${ }_{\left({ }^{10}\right)}$ Belisário Pimenta, António Augusto Gonçalves, in «António A. Gonçalves - Homenagem do Instituto de Coimbra», Coimbra, Coimbra Editora Limitada, 1946, p. 30. 
ou num misantropo desnervado. É assim que o vemos desempenhar as funções de vereador da Câmara Municipal de Coimbra, eleito pela minoria republicana, no triénio de 1887 a 1889, ao lado dos seus correligionários Manuel Augusto Rodrigues da Silva e Abílio Roque de Sá Barreto ( ${ }^{11}$ ). A sua opção de livre-pensador é demonstrada, em termos práticos, com a actividade dispendida na organização do cortejo cívico realizado em Coimbra, em 1890, e dedicado à memória de Joaquim António de Aguiar. E a tolerância do seu republicanismo irmana-o com esse tribuno de magnético carisma que foi António José de Almeida, director e proprietário de uma das mais demolidoras revistas publicadas na fase final do ataque republicano às instituições monárquicas, a Alma $\mathrm{Na}$ cional, cuja capa foi justamente concebida por António Augusto Gonçalves $\left({ }^{12}\right)$. De resto, os dirigentes republicanos manifestaram-lhe a sua confiança após o triunfo de 5 de Outubro, atribuindo-lhe, em 1912, a presidência da Comissão Administrativa do município conimbricense.

Referimos já, de passagem, o carinho de António Augusto Gonçalves pelas camadas mais desfavorecidas da população, e especialmente pelos operários. Ao seu serviço colocou o melhor da sua vocação pedagógica, quer como professor de Desenho na Associação dos Artistas e no Colégio dos Orfãos, quer como principal inspirador da tentativa de fundação, em 1881, do Centro Operário de Coimbra, que chegou a aprovar um manifesto e um projecto de estatutos, acabando por abor$\operatorname{tar}\left(^{(13}\right)$. Mas a sua principal realização neste domínio foi indubitavelmente a criação da Escola Livre das Artes do Desenho. Manuel Augusto Rodrigues da Silva, o seu futuro colega na vereação municipal republicana de $1887-89$, secundou-lhe os intentos. $\mathrm{O}$ primeiro problema que se colocava à viabilização da Escola era o da obtenção de um espaço físico onde os trabalhos pudessem decorrer. Daí que, no dia 31 de Julho de 1878 , sete operários tenham dirigido ao executivo municipal um requerimento rogando a mesquinha mercê de lhes ser cedida a antiga casa do Senado, no andar superior da torre do Arco de Almedina, na altura abandonada e em adiantado

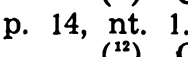

( $\left.{ }^{11}\right)$ Cf. Costa Rodrigues, Mestre Gonçalves de Coimbra, ibidem,

$\left.{ }^{12}\right)$ Cf. José Augusto Pimenta, António Augusto Gonçalves, ibidem, pp. 33-35 e Alberto Meira, Mestre Gonçalves, Viana do Castelo, Edição do Anuário do Distrito de Viana do Castelo, 1932, p. 6.

(13) Cf. Augusto Veiga, "António Augusto Gonçalves (Esboço biographico», A officina. Semanario da classe operaria de Coimbra, n. $48,29-11-1883$, p. 1 , col. 3 e p. 2 , col. 1-2. 
estado de ruína, para que nela se realizassem «sessões nocturnas de estudos de desenho e modelação, com aplicações a artes, indústrias e ofícios» $\left({ }^{14}\right)$. A Câmara Municipal anuiu à pretensão e forneceu mesmo alguns materiais para que o prédio fosse ligeiramente restaurado. Nos termos dos artigos $10^{\circ}$ e $2 .^{\circ}$ dos seus Estatutos, a novel associação, para além de propagar o estudo do desenho aplicado, deveria ainda promover "conferências públicas sobre assuntos artísticos», estabelecer "lições públicas e gratuitas para o ensino racional do desenho, destinadas a crianças de ambos os sexos e adultos e cursos regulares, onde fossem ministradas noções de estética, história de arte, estilos, etc», criar "uma caixa protectora para subsidiar nestes estudos indivíduos de vocação reconhecida, amantes do trabalho e carecedores de recursos», fundar "uma folha periódica de propaganda e instrução, destinada aos operários» e acalentar a "constante aspiração" de "promover, apenas as circunstâncias necessárias concorram, exposições locais de objectos de arte e manufacturas». Falava-se ainda na organização de um museu permanente e no incremento de um gabinete de leitura $\left({ }^{15}\right)$. Como se vê, a Escola Livre das Artes do Desenho viria a ser, na intenção dos seus fundadores, um importante organismo pedagógico e filantrópico, de escopo mutualista e promocional, basicamente voltado para a superação das insuficiências culturais e técnicas dos seus associados e beneficiários. A viabilização económica do projecto revelou-se muito difícil, já que se não dispunham de outras fontes de financiamento para além das muito módicas quotizações dos seus sócios efectivos e amadores, sendo inteiramente gratuitas as lições ministradas a crianças e adultos carecidos de meios financeiros. A Escola, reconhecendo esta debilidade, solicitaria, tempos depois, ao município, que inscrevesse no orçamento da sua gerência uma pequena verba para custeio das suas despesas correntes. Mas como o seu requerimento fosse indeferido, teve de procurar sobreviver sem a ajuda de qualquer apoio oficial $\left.{ }^{(16}\right)$. No seu regime de trabalho distinguiam-se as sesões das $2 .{ }^{\text {as }}$ e $5 .{ }^{\text {as }}$ feiras, destinadas aos sózios efectivos e amadores, das lições públicas e gratuitas, que decorriam às $4 .^{\text {as }}$ feiras e aos sábados. Foram

(14) Joaquim Martins de Carvalho, «Escola Livre das Artes do Desenho», O Conimbricense, n. $.^{\circ} 3780,6-11-1883$, p. 1 , col. 3 .

$\left({ }^{15}\right)$ «A Escola Livre das Artes do Desenho e a Exposição de Manufacturas por ella promovida», $A$ Officina, n. ${ }^{\circ} 37,13-9-1883$, p. 1 e p. 2 , col. 1 .

$\left.{ }^{16}\right)$ Alexandre da Conceição, «Escola Livre das Artes do Desenho», A Officina, n. ${ }^{\circ} 37,13-9-1883$, p. 2, col. 2-3 e p. 3, col. 1-2. 
deveras admiráveis os serviços prestados à cidade e à sua região pela Escola Livre das Artes do Desenho, espécie de cenáculo popular devotado às artes industriais, onde pontificava a característica figura de António Augusto Gonçalves. E com que saudosa ternura não viriam a ser evocadas, pelos seus antigos frequentadores, essas produtivas sessões de trabalho, onde, como nos diz Fernandes Costa, «à luz de bicos de gaz algumas dezenas de rapazes imberbes e de homens já feitos aplicavam alegremente as horas do seu descanso, uns fazendo os primeiros riscos a lápis ou carvão, outros copiando gessos, outros esforçando-se já nos difíceis desenhos de figuras, outros modelando o barro húmido, cobertos os ensaios de serapilheiras molhadas»! ( $\left.{ }^{17}\right)$. A influência directa ou indirecta da Escola faz-se sentir no aparecimento de uma brilhante vanguarda de artífices locais, de que se destaca a geração dos Costa Mota e os nomes de João Machado, José Barata, Manuel Martins Ribeiro, Manuel Pedro de Jesus, Lourenço Chaves Almeida, António Maria da Conceição e tantos mais, convertendo a personalidade de Augusto Gonçalves na "figura principal de um verdadeiro renascimento artístico» $\left({ }^{18}\right)$. As regiōes do poder, ainda que habitualmente refractárias a reconhecerem os méritos de inimigos políticos, acabaram por render-se à valia da obra que Gonçalves ia erguendo pedra a pedra. Quando, em 1884, se criou em Coimbra a Escola de Desenho Industrial Brotero, o seu nome passou a integrar o elenco do pessoal docente. Esta Escola seria ampliada em 1889 e convertida em Escola Industrial Brotero através da arrojada reforma do ministro Emídio Navarro, marechal do partido progressista. Mestre Gonçalves, designação respeitosa que já então lhe era atribuída, foi nomeado seu director, desenvolvendo nela uma proveitosa gestão administrativa e pedagógica.

António Augusto Gonçalves não terminaria a sua longa existência sem realizar duas obras que, pela sua importância artística e relevo cultural, bastariam para conferir ao seu autor o direito de passar a ser reverentemente lembrado pelas gerações coimbrãs: referimo-nos ao restauro da Sé Velha e à fundação do Museu Machado de Castro. Na primeira destas realizações deixou ele "um belo testemunho da sua probi-

(ii) F. Fernandes Costa, Grande Mestre e Grande Cidadão, in "António A. Gonçalves - Homenagem do Instituto de Coimbra", Coimbra, Coimbra Editora Limitada, 1946, p. 68.

${ }^{(18)}$ João Couto, O Professor António Augusto Gonçalves, fundador do Museu de Machado de Castro, Coimbra, Tip. da Coimbra Editora Limitada, 1946, p. 6. 
dade, do seu gosto e da sua cultura", segundo o depoimento de Eugénio de Castro $\left.{ }^{(19}\right)$. E não deixa de ser agradável constatar que nessa obra de restituição à originalidade arquitectónica se encontram combinadas as vontades do livre-pensador Gonçalves, apóstolo da glória dos homens, e do prelado D. Manuel de Bastos Pina, apóstolo da glória de Deus. Quanto à instalação, organização e conservação do Museu Machado de Castro, criado pela legislação republizana de 1911, deverá referir-se que se tratou de um tipo de trabalho em que António Augusto Gonçalves já se encontrava rotinado. Fora ele que salvara da decadência total o Museu de Arqueologia do Instituto de Coimbra, em meados da década de 90, e que pela mesma altura, por sugestão do Bispo-Conde, reunira no chamado Tesouro da Sé o conjunto das preciosas alfaias litúrgicas, paramentos, tapeçarias e bordados de instituições religiosas da diocese, obstando aos inconvenientes da sua dispersão ou eventual descaminho. Estes dois valiosíssimos núcleos museológicos foram depois transferidos, em datas distintas, para o Museu Machado de Castro e incorporados no seu património.

E evidente que nesta breve resenha biográfica se acham omitidas muitas particularidades da vida de Mestre Gonçalves. Não se detalham os primores do jornalista e do crítico de arte, as arremetidas do polemista ou os méritos do professor universitário, que também foi. Mas consignam-se aspectos suficientes para qualificar de generosa e útil uma vida que se extinguirá em 4 de Novembro de $1932\left({ }^{20}\right)$.

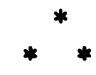

Em 11 de Agosto de 1883, nas colunas do seu Conimbricense, Joaquim Martins de Carvalho anuncia que acabava de se formar uma comissão, presidida por ele e secretariada por António Augusto Gonçalves e Manuel Augusto Rodrigues da Silva, com o fim de levar a efeito uma Exposição industrial

(19) Eugénio de Castro, Cartas de torna-viagem, t. 1. ${ }^{\circ}$, Coimbra, «Lumen» - Empresa Internacional Editora, 1926, p. 162.

$\left.{ }^{(20}\right)$ Os estudiosos da personalidade literária e artística de António Augusto Gonçalves defrontam-se com o problema da fixação da sua produção bibliográfica, bastante complexo, devido ao uso de diversas iniciais e pseudónimos e ao anonimato de outros escritos. Neste particular, revelar-se-á proveitosa a leitura de A. G. da Rocha Madahil, Tentativa da bibliografia de Mestre António Augusto Gonçalves, insigne escritor e artista conimbrigense, Coimbra, Coimbra Editora Limitada, 1947. 
no âmbito do distrito. Os motivos que assistiam à comissão executiva para que o certame se realizasse são definidos nestes termos, segundo as palavras do seu presidente: «Decorreram já 14 anos desde que por iniciativa da Associação dos Artistas se fez nesta cidade a primeira exposição distrital; e por isso é ocasião de confrontar as duas exposições e ver se as indústrias têm desde então estacionado, ou se têm progredido. A próxima exposição é toda prática. Trata-se de saber quais as circunstâncias em que se acham todos os ramos de actividade industrial deste distrito de Coimbra» $\left({ }^{21}\right)$.

A comissão que acabava de constituir-se colocar-se-ia ao serviço da Escola Livre das Artes do Desenho, sob os auspícios da qual o certame se realizaria.

Uma vez escolhidos os agentes e definidos os objectivos, o passo seguinte seria a sensibilização da opinião pública e a obtenção de comparticipações financeiras, que não poderiam esperar-se da associação patrocinadora, dadas as suas notórias carências. A propaganda fundamental da Exposição competiu ao Conimbricense que, número após número, passou a historiar todos os esforços preparatórios, e ao jornal A Oficina, de cariz vincadamente operário e oposicionista. Os demais periódicos políticos da cidade, não obstante haverem sido instados pela comissão executiva a coadjuvar o empreendimento, limitaram o seu apoio a breves referências de circunstância $\left({ }^{22}\right)$. O mesmo não poderá dizer-se das autoridades locais, excepção feita ao próprio município, que se limitou a acompanhar de longe, com estranha passividade, todas as diligências. Assim, o governador civil recomendou a iniciativa aos serviços dele dependentes; o director da repartição das obras do Mondego autorizou a utilização das madeiras do Choupal para os trabalhos de marcenaria que o certame exigisse; e a Junta Geral do Distrito estabeleceu um subsídio e votou um prémio pecuniário destinado à secção da indústria agrícola. Também se resolveu com facilidade o problema das instalações, dado que a comissão executiva obteve do Definitório da Ordem Terceira da Penitência autorização para que lhe fosse franqueado o seu edifício do extinto colégio do Carmo, na rua da Sofia,

$\left({ }^{21}\right)$ Joaquim Martins de Carvalho, «A Exposição Distrital», O Conimbricense, n. ${ }^{\circ} 3795,29-12-1883$, p. 1 , col. 1 .

${ }^{22}$ ) «Os periodicos politicos d'esta cidade, com excepção de dois...., limitaram-se ha tempo a annunciar em breves palavras a exposição das manufacturas d'este districto, e ainda para isso foi mister que a comissão executiva lhes dirigisse uma carta pedindo-lhes a sua coadjuvação» (Luis $\mathrm{H}$. Cardoso, «A Exposição e a imprensa de Coimbra», $A$ Officina, n. ${ }^{\circ} 45,9-11-1883$, p. 2, col. 3 ). 
há pouco reconstruído, e que se encontrava, ao tempo, devoluto. Constituiram-se também comissões regionais de apoio, muitas delas trabalhando em íntima solidariedade com os representantes do poder local e com os párocos. A resposta da indústria distrital superou as expectativas, pelo que o espaço inicialmente previsto para os expositores teve de alargar-se, mediante a concessão de novas facilidades, requeridas e obtidas junto da Ordem Terceira. Em 1 de Janeiro de 1884 Coimbra inaugurava, com o luzimento da praxe, a sua Exposição Distrital de Manufacturas $\left({ }^{23}\right)$. $\mathrm{O}$ número total dos expositores, tanto individuais como representativos de unidades fabris, deveria ter rondado as seis centenas. As mercadorias e produtos expostos distribuiam-se por grupos de afinidade e iriam ser apreciados por sub-comissões técnicas, a quem incumbiria a responsabilidade da atribuição de distinções, ou seja, a concessão de medalhas de ouro, prata e cobre ou de simples menções honrosas. Embora a Exposição abrisse todos os dias as suas portas ao público interessado, às quartas feiras e domingos havia o aliciante suplementar da iluminação eléctrica e dos concertos executados pelas filarmónicas Boa União e Conimbricense. Contudo, nem a presença em Coimbra de um engenheiro belga destacado para esta cidade pela Companhia Geral de Luz Eléctrica, de Bruxelas, nem a vinda das máquinas da casa real, nem o gracioso empréstimo das lâmpadas do senhor Visconde de Castanheira de Pera impediram que, por deficiências técnicas sucessivas, se regressasse, talvez com uma ponta de melancolia, à iluminação a gaz.

A comissão executiva decidiu também publicar uma $R e$ vista Ilustrada da Exposição Distrital de Coimbra de 1884, tendo sido dados ao prelo quatro números, entre Janeiro e Abril. Para além do seu belo aspecto gráfico, valorizado ainda pelos desenhos de António Augusto Gonçalves, os números desta revista contêm os juizos técnicos de alguns especialistas, àcerca dos produtos expostos numas quantas secções. São eles invariavelmente encomiásticos quanto à qualidade técnica da fabricação, mas também sistematicamente reticentes quanto ao bom gosto e nível estético das mercadorias apreciadas. António Augusto Gonçalves lastima, em relação

$\left({ }^{23}\right)$ No trabalho do meu Colega e Amigo José Maria Amado Mendes, «Exposições industriais em Coimbra na segunda metade do século XIX», $O$ Instituto, t. CXXXIX, Coimbra, 1979, pp. 35-55 encontramos esclarecedoras achegas sobre a Exposição Distrital de 1884 a pp. 41-48. Também nele se trata da Exposição Distrital de 1869 e da Exposição Industrial da freguesia de Santa Clara, ocorrida em 1894. 
à secção de cerâmicas, "a falta enorme de instrução artística com que estão lutando os industriais» $\left.{ }^{24}\right)$, indo ao ponto de desabafar deste modo: "Ora eu, àcerca da faiança de Coimbra, devo confessar que professo esta opinião radical: ou lhe dão escola, ou a matam. Não é propriamente no fabrico, na técnica, que está o defeito capital;....o que me faz reclamar é a penúria da arte» $\left({ }^{25}\right)$. Um outro crítico, debruçando-se sobre a secção de mobiliário, reconhece que "aos nossos artistas não falta geralmente habilidade, e a prova é que reproduzem satisfatoriamente qualquer modelo; porém falta-lhes educação artística, orientação estética" $\left({ }^{26}\right)$. Sobre a secção de ferros e serralhar ria batida declara-se que "o serralheiro conimbricense tem a posse completa do processo de trabalho, a mestria que dá a prática. ....Quando se trata do gosto o caso muda um poucon $\left({ }^{27}\right)$. E até àcerca dos bordados, rendas e tapeçarias apresentadas no certame pelas senhoras do distrito de Coimbra se adiantam estas palavras severas: "Estes trabalhos.... que representam muita aptidão, paciência e aplicação, punham em evidência, de maneira muito frisante o atraso da educação artística da senhora portuguesa. Que detestáveis padrões, que deploráveis desenhos e que precioso tempo gasto em bordados a escumilha e outras frioleiras de morosíssima e enfadonha execução e de efeito menos que medíocre! Com algum desenho e alguns bons modelos aquelas senhoras fariam maravilhas!" ( $\left.{ }^{28}\right)$. Também Joaquim de Vasconcelos acompanhava 0 tom geral: "O distrito não tem uma simples escola oficial de desenho, quanto mais um curso de arte, no qual se daria, além da modelação, um curso histórico sobre os estilos de arte» $\left({ }^{29}\right)$.

Durante o período em que a Exposição se manteve aberta ao público decorreu um ciclo de conferências, de que se encarregaram Augusto Filipe Simões, Joaquim de Vasconcelos, Alexandre da Conceição, Augusto Rocha e António Cândido. Salvo a última, proferida pela Aguia do Marão, qualificativo com que Oliveira Martins distingưia António Cândido, que foi indiscutivelmente um dos grandes oradores do seu tempo,

(2) A. Gonçalves, «A ceramica na Exposição Districtal de Coimbra», Revista Illustrada da Exposição Districtal de Coimbra em 1884, n. ${ }^{\circ}$ 2, Fevereiro de 1884, p. 20.

$\left.{ }^{(25}\right)$ A. Gonçalves, «A ceramica na Exposição Districtal de Coimbra», Revista Illustrada..., n.० 3, Março de 1884, pp. 39-40.

${ }^{(*)}$ A. Barbosa, «Mobiliario», ibidem, n. ${ }^{\circ} 2$, p. 29. de 1884, p. 62 .

(") A. Gonçalves, «O ferro na Exposição», ibidem, n.॰ 4, Abril

$\left.{ }^{28}\right)$ (Diversos apontamentos», ibidem, n. ${ }^{\circ} 4, \mathrm{pp}$. 65-66.

$\left({ }^{\infty}\right)$ Joaquim de Vasconcelos, «As bellas artes na Exposição de Coimbra», ibidem, n. ${ }^{\circ} 4$, p. 49. 
todas as demais decorreram na presença de uma limitada assistência. $\mathrm{O}$ cronista do Tribuno Popular, folha bi-semanal que então se publicava em Coimbra, vituperava o divórcio da cidade relativamente aos seus acontecimentos culturais, dizendo: «A maioria dos sábios desta boa terra têm pelas conferências e pela exposição a mesma indiferença que os governos têm pelas artes e pelas indústrias" $\left({ }^{30}\right)$. Com efeito, também 0 afluxo de visitantes à Exposição ficou aquém do que poderia esperar-se, já que o número das 6000 pessoas que se decidiram a desembolsar os 200 ou 100 reis de entrada - a comissão executiva decidiu baixar o preço dos bilhetes de ingresso a partir de 6 de Fevereiro - pode considerar-se pouco significativo, especialmente se tivermos presente o facto de se tratar de uma realização de interesse distrital.

Deixamos deliberadamente para o fim o tratamento de uma questão aliciante: a Exposição manufactureira de Coimbra de 1884 teria tido, no ânimo explícito ou implícito dos seus promotores, algum significado político? Será possível descobrir nela algum traço ideológico, ainda que vestigiário? Cremos sinceramente que sim e vamos tentar prová-lo.

Lembremos primeiramente o posicionamento político dos seus promotores mais responsáveis. Joaquim Martins de Carvalho, presidente da comissão executiva, era um velho liberal de tradição setembrista e patuleia, que já nos começos da década de 80 ovacionava no seu Conimbricense os triunfos eleitorais republicanos e que acompanhava esse partido, a que viria a aderir em provecta idade, na crença, mais ou menos messiânica, de um próximo ressurgimento nacional. Os dois secretários, António Augusto Gonçalves e Manuel Augusto Rodrigues da Silva, eram dois homens de sentimento vincadamente anti-monárquico, que acompanharam de perto e de forma militante o projecto republicano, como já vimos. A Escola Livre das Artes do Desenho, associação promotora da Exposição, assumiu desde o início uma feição de mutualismo filantrópico que a afastava, de todo em todo, dos processos preferidos pela plutocracia dominante, monturo em que o regime vigente se atascava lentamente.

E evidente que os promotores da Exposição não poderiam conferir-lhe, atentas as circunstâncias, um significado radicalmente oposicionista; e poderá mesmo admitir-se como provável que a forma de protesto implícito não teria sido pressentida, ou sequer desejada, por muitos dos que inter-

${ }^{30}$ ) A Exposição Districtal», O Tribuno Popular, n..$^{\circ} 2919$, 6-2-1884, p. 3, col. 1 . 
pretaram o empreendimento meramente como um despertar de Coimbra para "o movimento da época actual", deixando a cidade universitária finalmente de ser aquela «boa menina pachorrenta, eterna e exclusivamente ocupada em chupar as têtas da velha Minerva» $\left({ }^{31}\right)$. Mas o rasto ideológico deve procurar-se na subtileza dos motivos, na meia palavra dos argumentos, no lume vago das mais recônditas intenções. $E$ isto sobretudo em formas de actividade que precisam do mecenato dos mandantes para poderem afirmar-se. Ora o ponto $2 .^{\circ}$ das "condições regulamentares" do certame decretava o seguinte: «Para inteiro conhecimento da índole deste certame é recomendado aos industriais que na apreciação das diversas manufacturas não se atende unicamente à sua raridade, à perfeição da mão de obra, ao seu valor e riqueza; mas especialmente à utilidade que representam, às necessidades a que satisfazem, à propriedade das suas aplicações, às suas qualidades técnicas e à importância que devem ter no mercado, embora possam parecer ordinárias e vulgares" $\left({ }^{32}\right)$. Talvez seja excessivo substituir aqui a palavra mercado pela palavra sociedade e sustentar que, em última análise, se não está a falar de mercadorias mas de pessoas e da importância que elas devem ter «embora possam parecer ordinárias e vulgares». Mas em nenhum excesso incorremos quando interpretamos a cláusula como um convite a que a Exposição viesse a ser um acontecimento bem próximo das necessidades reais da população e não uma espectaculosa parada de mercadorias sofisticadas e dispendiosas. Atente-se agora no queixume de António Augusto Gonçalves, inserto na Revista Ilustrada da Exposição, quando regista que a miséria e a fome dos sítios mais rústicos condenam as comunidades à emigração: "a olaria das aldeias está definhando de miséria; e o desespero vai-se apossando do pobre oleiro cansado de fadiga e de fome. $O$ triste recurso da emigração já entrou com eles: ainda há pouco do concelho de Miranda uma leva partiu para o Brasil» $\left({ }^{33}\right)$. Aqui já não há a fragilidade de um subentendido, mas antes o vigor de um protesto.

O crítico que na Revista Ilustrada se ocupa da seç̧ão de mobiliário, considerando que os tipos de móveis preferidos pelo tempo que passou são dificilmente susceptíveis de inte-

${ }^{\left({ }^{3}\right)}$ J. Nazareth, «Coimbra», Revista Illustrada..., n. ${ }^{\circ} 4$, Abril de 1884, p. 74 .

${ }_{\left({ }^{32}\right)}$ "Condições regulamentares», O Conimbricense, n. ${ }^{\circ} 3756$, 14-8-1883, p. 1, col. 2.

${ }^{(3)}$ A. Gonçalves, " A Ceramica na Exposição Distríctal de Coimbra», Revista Illustrada..., n. ${ }^{\circ}$ 2, Fevereiro de 1884, p. 19. 
grar a decoração das habitações de então, sentencia também: «A obra que actualmente produzem os nossos artistas, não tem em geral carácter pronunciado em ordem a um determinado ideal, antes apresenta mistura e confusão, em grande parte motivadas pelo sentimento dominante de luxo banal e burguez. Com a marcenaria deu-se ainda uma circunstância, que certamente deve ter retardado o seu desenvolvimento: - foi a mania de mobilar à antiga» ${ }^{(3)}$ ). Vamos resistir à tentação de forçar o texto e de comparar os serventuários monárquicos a móveis de um regime à antiga, sem um «carácter pronunciado em ordem a um determinado ideal" - abra-se aqui um breve parêntesis só para referir que são muitos os republicanos que singularizam o regime sonhado com a expressão maiúscula "o Ideal» - para nos atermos a uma interpretação meramente enunciativa. $\mathrm{Na}$ linha do discurso anterior, também aqui se prefere a sobriedade ao "luxo banal e burguês» das oligarquias financeirąs. A letra do hino da Exposição, da autoria do conhecido publicista republicano Alexandre da Conceição, colaborador do jornal $O$ Século, quase desde o seu início, fornece-nos outros elementos que abonam a nossa interpretação. Destaquemos duas quadras:

«Na conquista gloriosa da terra

Pelo braço potente do bem

São as artes que fazem a guerra

Que a ciência dirige e mantém»

«Esta terra da pátria querida

Morre à míngua de força e de luz

Infundamos-lhe pois nova vida

Companheiros na luta, eia! sus!» $\left({ }^{35}\right)$

A primeira destas quadras tem um perfume acentuadamente positivista. Com efeito, a maior parte dos nossos republicanos, na esteira de Saint-Simon e de Comte, contrapõe às extorsões e aos direitos de conquista sancionados pela violência do militarismo, inerentes a todos os regimes monárquicos, as pacíficas e imbeles realizações de uma indústria norteada pelo critério científico e só susceptível de frutificar plenamente no "normal» regime republicano. A dicotomia bem-mal soldam-se as dicotomias paz-guerra, industrialismo-militarismo, república-monarquia.

\footnotetext{
(34) A. Barbosa, «Mobiliario», ibidem, n. ${ }^{34}$, p. 29.

$\left.{ }^{35}\right)$ «Hymno da Exposição», O Conimbricense, n. ${ }^{\circ} 3796,3-$ $-1-1884$, p. 2 , col. $1-2$.
} 
A segunda quadra desenvolve um tema persistentemente glosado pelo republicanismo da década de 80: o da pátria agonizante, que será salva pela combatividade dos seus filhos mais autênticos. Com efeito, a ideia de revivescência da nação portuguesa é uma noção medular, sem a qual fica por entender aquela plenitude místico-patriótica com que foram celebrados os centenários camoneano e pombalino de 1880 e 1882 . Teófilo Braga exprime com toda a justeza este ponto: «O Centenário de Camões neste momento histórico e nesta crise dos espíritos tem a significação de uma revivescência nacional. Teremos neste organismo ainda as energias para que um povo se afirme perante a história? A resposta depende da realização do Centenário, em 10 de Junho de 1880" $\left({ }^{30}\right)$. Mais lapidar, o mesmo asseverava Ramalho Ortigão, nas Farpas: «Estas comemorações são como a prova do espelho posto à boca do moribundo" $\left({ }^{37}\right)$. Por outro lado, atendendo à contaminação positivista do nosso republicanismo, não surpreende que tanto as Exposições como os Centenários e os Congressos sejam vistos como a expressão laicizada das vertentes activa (Exposições), afectiva (Centenários) e racional (Congressos) em que se resolve a antropologia positivista, e que as efemérides das celebridades nacionais sejam encaradas como outros tantos momentos de fervor sociocrático.

Porém, o clamor da ideologia e da combatividade política atinge o seu auge no repto lançado aos trabalhadores por Felizardo Lima, nas páginas do jornal $A$ Oficina, incitando-os a que aproveitassem o ensejo da Exposição para a definitiva constituição da Associação dos Trabalhadores Portugueses. Felizardo Lima, que, sem visos de exagero, pode ser designado

${ }^{\left({ }^{8}\right)}$ Teófilo Braga, «O Centenário de Camões em 1880», $O$ Positivismo, Segundo Ano, n..$^{\circ}$, Outubro-Novembro de 1879, p. 4.

${ }^{\left({ }^{37}\right)}$ A mística republicana que as festas do centenário camoneano vieram potenciar detecta-se na própria terminologia utilizada por alguns dos mais notáveis espíritos que moviam guerra à monarquia. António José de Almeida vai ao ponto de utilizar uma linguagem sacra quando afirma, referindo-se à reorganização republicana tentada nos inícios de 1903, no discurso que proferiu nos funerais de Rafael Bordalo Pinheiro: «Mas o grande partido, que a estas horas ensaia o último esforço para a realização do seu velho anseio, recebeu a sua sagração e o seu baptismo como partido nacional no centenário de Camões. Essa festa à memória do grande português dos «Lusíadas» foi o prólogo da ressurreição da nossa raça.... Pois bem: nessa festa foi o pulso ilustre de Rafael Bordalo que pôs, na fronte erguida do meu partido, os santos óleos da Revolução!» (António José de Almeida, Rafael Bordalo Pinheiro, in «Quarenta Anos de Vida Literária e Política», t. 1., Lisboa, J. Rodrigues e C..$^{\circ}$ 1933, pp. 95-96). Os itálicos são da nossa responsabilidade. 
como um dos mais radicais republicanos do seu tempo, exorta os trabalhadores à organização de uma associação de classe trans-regional, que finalmente lhes desse voz: «A aristocracia tem a camara dos pares, a burguesia tem a camara dos deputados, mas os trabalhadores nem nas juntas de paróquia fazem ouvir a sua voz», dizia. E continuava: «Hoje, que os banquetes estão na ordem do dia, combine-se também um banquete modesto em Coimbra, num dos dias da exposição, e aí lancem-se as bases da Assosiação Nacional dos Trabalhadores, e à luz sagrada que essa exposição reflectir redijam-se uns estatutos provisórios, e um manifesto aos trabalhadores combinando-se um congresso em que, delegados de todas as classes dos trabalhadores do país, vão constituir definitivamente a grande e emancipadora Associação dos Trabalhadores Portugueses» $\left({ }^{38}\right)$.

De resto, todas as presunções de inocuidade política da Exposição caem por terra perante a espontânea manifestação que as duas mais importantes associações operárias de Coimbra, a Associação dos Artistas e a Escola Livre das Artes do Desenho, decidem conjuntamente fazer à comissão executiva e especialmente ao seu presidente, em 2 de Março de 1884, dia do encerramento da Exposição.

Em suma, e a concluir, diremos que a Exposição Distrital das Manufacturas, para além de ter demonstrado a vitalidade das indústrias da região conimbricense nos fornece índices insofismáveis daquela republicanização mental que haveria de conduzir o nosso país à revolução de 5 de Outubro de 1910.

${ }^{(8)}$ Felizardo Lima, «Exposição Industrial de Coimbra», $A$ Officina, n. $46,15-11-1883$, p. 2, col. 1 . 